Boletín de la Sociedad Geológica Mexicana

VOLUMEN 66, NÚM. 2, 2014, P. 247-261

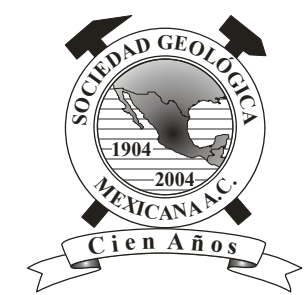

\title{
Inundaciones por agua subterránea en zonas costeras. Caso de estudio: acuífero de Veracruz
}

\author{
Iris Neri Flores ${ }^{1, *}$, Oscar A. Escolero Fuentes ${ }^{2}$, Sara Pérez Torres ${ }^{3}$, Guadalupe Riquer Trujillo \\ ${ }^{1}$ Posgrado en Ciencias de la Tierra Instituto de Geología Universidad Nacional Autónoma de México Ciudad Universitaria. \\ C.P.04510. México, D.F. \\ ${ }^{2}$ Instituto de Geología. Departamento de Geología Regional. Universidad Nacional Autónoma de México Ciudad Universitaria. \\ C.P.04510. México, D.F. \\ ${ }^{3}$ Instituto de Ingeniería, Universidad Veracruzana, Av. S. S. Juan Pablo II, s/n, Campus Mocambo, Fracc. Costa Verde, C.P. 94294 , \\ Boca del Río, Veracruz. \\ *irisneri@gmail.com
}

\begin{abstract}
Resumen
El manejo del riesgo en inundaciones debe ser entendido como parte integral de las interacciones del ciclo hidrológico, en donde el ascenso de niveles freáticos puede generar zonas inundables por agua subterránea. La metodología empleada para identificar este fenómeno fue el monitoreo mensual de mediciones de profundidad del nivel freático durante el año 2012, mediante una red de monitoreo de 27 norias, nueve piezómetros y el registro de precipitación diaria en una planicie de inundación de la zona costera de Veracruz. Los resultados muestran que existe una variación temporal del nivel freático e indican que la temporada de menor nivel tiene lugar en mayo, y que ocurren ascensos de hasta $2-3 \mathrm{~m}$ en septiembre. En la zona de estudio, el ascenso de niveles freáticos evidenció tres casos de inundaciones por agua subterránea que tuvieron períodos de inundación hasta por cuatro meses. Este trabajo pone en evidencia la presencia de zonas inundables por agua subterránea, la cual debe ser tomada en cuenta para la gestión del riesgo por inundaciones en áreas con niveles freáticos someros de zonas costeras.
\end{abstract}

Palabras clave: inundaciones, agua subterránea, nivel freático, zona costera, Veracruz.

\begin{abstract}
Flood risk management must be understood as an integral part of the hydrological cycle, where the rise of groundwater levels can produce groundwater flooding due to subterranean water. The methodology applied to identify this phenomena in a coastal flooding area in Veracruz was monthly monitoring, during 2012, of water table depth by installing a network of 27 shallow groundwater wells, piezometers and daily measurements of precipitation. The results show that there is a temporal variation of the water table, where the lowest level season was in May and rose as much as to $2-3 \mathrm{~m}$ during September. In the study area, groundwater rise was evident in three cases of groundwater flooding that lasted for periods of up to four months. This work shows evidence of the existence of flooding areas due to subterranean water, which has to be taken into consideration in flood risk management in areas with shallow groundwater levels in coastal zones.
\end{abstract}

Keywords: flooding, groundwater, phreatic level, coastal zone, Veracruz. 


\section{Introducción}

Durante el periodo 2000 a 2013, fueron reportados 2247 eventos relacionados con el agua en la base de datos de emergencias por desastres, matando a más de 73159 personas y afectando a más de 1300 millones de personas con daños económicos superiores a 321 mil millones de dólares a nivel mundial (EM-DAT, 2013).

En ICHARM (2009), se definió que entre los factores que hacen más vulnerables los desastres se encuentran: la variabilidad climática, la deficiencia en sistemas organizacionales, el ordenamiento territorial y los factores educativos; como el establecimiento de población en zonas de riesgo.

Una inundación se define como aquel evento que debido a la precipitación, el oleaje, la marea de una tormenta, o la falla de alguna estructura hidráulica, provoca un incremento en el nivel del agua de los ríos o del mar, generando invasión o penetración de agua en sitios donde usualmente no la hay (Salas y Jiménez, 2007). Para el análisis del riesgo por inundaciones se deben considerar tres componentes (Oumeraci, 2011), éstas son: 1) fuentes, 2) rutas y 3) receptores, a través de la cadena de riesgo. Las fuentes están relacionadas con los fenómenos naturales que dan origen a una inundación. Las rutas son las trayectorias que dan paso a la inundación y que pueden disminuirse con sistemas de defensas, y los receptores son aquellas áreas que pueden ser afectadas por la inundación produciendo daños. El análisis de inundaciones se ha enfocado principalmente al análisis de cuencas y modelación de avenidas (EXCIMAP, 2007). Adicionalmente Hankin et al. (2008) incluyen inundaciones por tsunamis e inundaciones por agua subterránea. McKenzie et al. (2010) definen a una inundación por agua subterránea cuando el nivel freático aumenta en respuesta a una recarga excepcional hacia la superficie de la tierra o hacia un punto donde la infraestructura subsuperficial es afectada y se ha reconocido como un tópico importante con impactos económicos. Cobby et al. (2009) proponen técnicas que se pueden aplicar en datos disponibles, y señalan limitaciones para producir mapas de inundación por agua subterránea.

Macdonald et al. (2007) evidenciaron que, en un acuífero somero permeable, la aparición de agua subterránea es el primer signo de alerta de una inundación para muchos residentes. Finch et al. (2007) realizaron una evaluación preliminar del riesgo de inundaciones por agua subterránea, monitoreando la humedad del suelo y niveles de agua subterránea. Alconada et al. (2010) investigaron, a través de la identificación hidrogeoquímica, que el agua de inundación se relaciona con la descarga de agua subterránea de flujos locales e intermedios. Belousova (2011) propone una metodología determinística y probabilística para evaluar el riesgo de inundaciones subsuperficiales, entendiéndose este concepto como un aumento del nivel freático. Actualmente, la investigación de inundaciones por agua subterránea se enfoca a los mecanismos que producen la inundación, la modelación de inundaciones por agua subterránea y el mapeo de áreas susceptibles a inundación (BGS, 2010). Este fenómeno no se ha estudiado en planicies costeras mexicanas, por lo que la inundación por agua subterránea no debe ser ignorada. El presente trabajo de investigación tiene como objetivo evidenciar la ocurrencia de inundaciones por agua subterránea, presentando tres situaciones características en que ocurre este fenómeno en una zona costera de Veracruz. Esto implica una nueva perspectiva en el manejo de inundaciones que considere los niveles freáticos y su variación temporal en zonas inundables de planicies costeras.

\section{2. Área de estudio}

El estado de Veracruz se ubica en la planicie costera del Golfo de México, contiguo a la cadena de montañas altas de la Sierra Madre Oriental, y es uno de los estados mexicanos con mayor incidencia de inundaciones, con un promedio de 3.5 inundaciones por año (Ortiz et al, 1992). Son importantes las inundaciones registradas en los años 1999, 2005 y 2010, las cuales acontecieron cuando la temporada de lluvias estaba concluyendo (Tejeda y Ochoa, 2007; Tejeda et al., 2012). En la planicie costera, en la cuenca baja de los ríos Jamapa y Cotaxtla, el área susceptible de inundación se localiza por debajo de la curva de nivel de 10 m.s.n.m. Para este trabajo se seleccionó una zona piloto de $32 \mathrm{~km}^{2}$, la cual se localiza en la confluencia de los ríos Jamapa-Cotaxtla, y engloba a los poblados de El Tejar, Medellín y Paso del Toro. Las coordenadas del área de estudio se encuentran entre los paralelos UTM X: 796428 y 801790 y los meridianos UTM Y: 2107153 y 2113217 . En esta zona la geología corresponde principalmente a sedimentos aluviales del Cuaternario, y el suelo es de tipo vertisol (INEGI, 1987). En la zona costera existe un acuífero libre con niveles freáticos someros cuyas profundidades varían entre 5 y $15 \mathrm{~m}$ (Neri, 2007). El área de estudio se inundó a consecuencia de las fuertes lluvias ocasionadas por el huracán Karl en el año 2010. En este caso, la altura de inundación tuvo un promedio de $1.04 \mathrm{~m}$, un mínimo de $0.1 \mathrm{~m}$ y un máximo de $3.5 \mathrm{~m}$. Las máximas alturas de inundación corresponden a la superficie localizada entre las poblaciones de El Tejar y Paso del Toro, y son zonas no adyacentes a las riberas de los ríos (Hueto, 2012; Figura 1).

\section{Materiales y métodos}

\subsection{Red de monitoreo}

Para conocer la variación temporal de niveles freáticos se realizó un censo de aprovechamientos. Gracias a éste se identificaron 62 obras de captación de agua subterránea en la zona de estudio, llamadas norias, que consisten en perforaciones en el subsuelo de $1 \mathrm{~m}$ de diámetro, en 

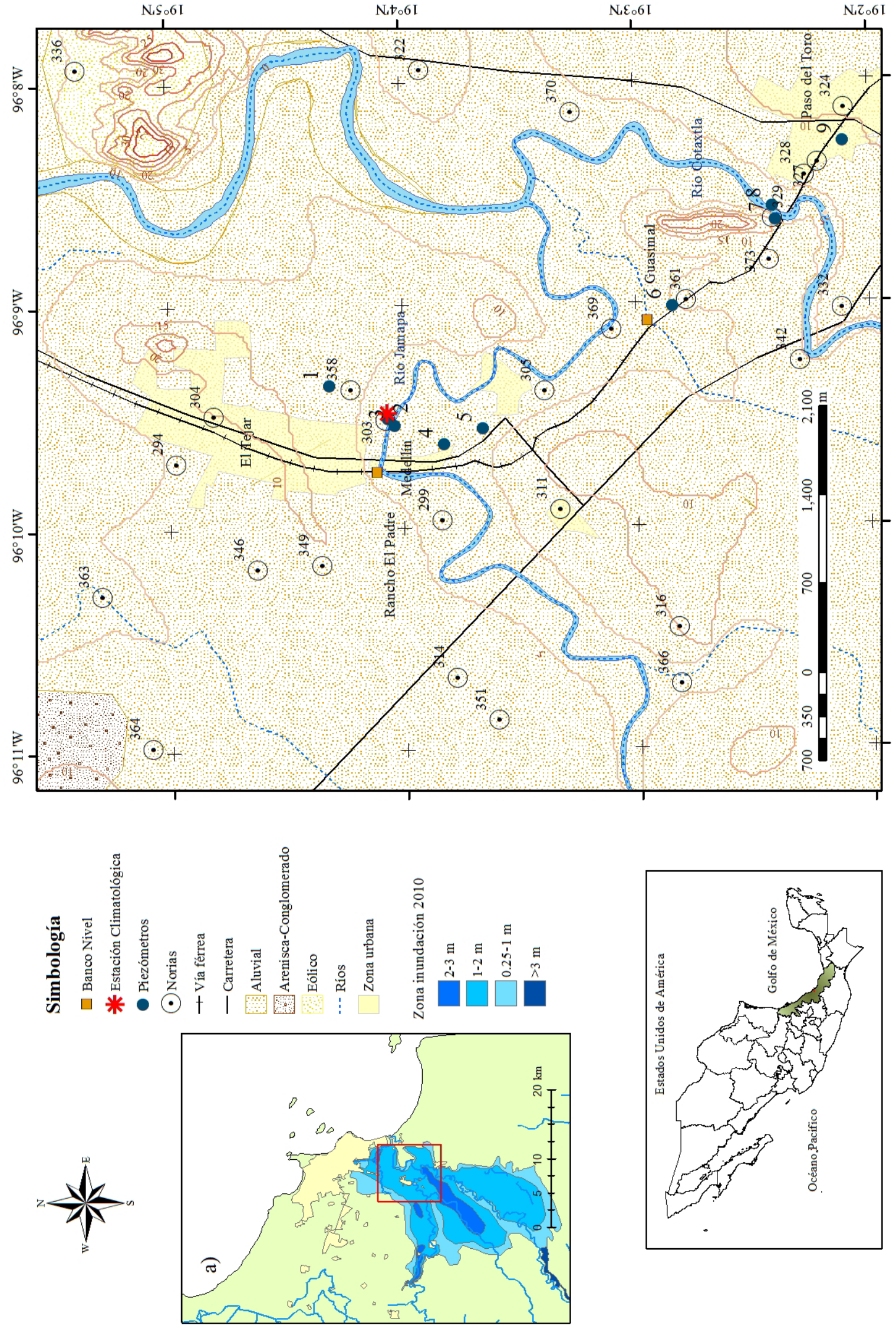

Figura 1. Zona de estudio y localización de sitios de monitoreo. En el recuadro a), se presenta la zona de inundación durante el evento del huracán Karl en el año 2010 
promedio, y con un brocal de tabique. De todas ellas, se estableció una red de monitoreo de 27 norias, por considerarse representativas del sitio y por su accesibilidad para realizar las mediciones. Además, se instalaron 9 piezómetros, los cuales se nivelaron topográficamente para referirlos al nivel medio del mar. Finalmente, se estableció otro punto de medición en la estación climatológica de El Tejar, a cargo de la Comisión Nacional del Agua-Golfo Centro, y donde se recopilaron datos diarios de temperatura, precipitación y evaporación. Las mediciones de profundidad del nivel estático, tanto en las 27 norias seleccionadas, como en los 9 piezómetros, se realizó in situ, con el apoyo de una sonda eléctrica con marcas graduadas en $\mathrm{cm}$. Se realizaron mediciones mensuales de profundidad del nivel estático durante el período comprendido entre enero 2012 y diciembre de 2012. A partir de abril de 2012, se iniciaron las mediciones del nivel estático de los piezómetros, debido a que en esta fecha se construyeron. En la Figura 1, se presenta la localización de norias $(\mathrm{N})$, piezómetros $(\mathrm{Pz}) \mathrm{y}$ de la estación climatológica (EC). Esta red de monitoreo fue georeferenciada, utilizando un GPS Garmin, según la proyección UTM Zona 14 Datum WGS84. En la Tabla 1 se presenta la localización de las norias, y el promedio de profundidad del nivel estático durante el año 2012. El nivel del terreno de las norias fue obtenido con una imagen Lidar (INEGI, 2010) con una resolución espacial de $5 \mathrm{~m}$.

\subsection{Instalación de piezómetros}

La instalación de los 9 piezómetros se ubicó en el tramo que se encuentra entre las poblaciones de El Tejar y Paso del Toro, empleando un equipo manual que consta de nueve extensiones de tubos de acero, que se conectan entre sí con una barrena y un maneral en forma de " $T$ ". En general, el procedimiento de perforación consiste en unir la barrena, las extensiones y el maneral, con apoyo de los conectores. Según el tipo de suelo, se selecciona un tipo de barrena diferente. La perforación es manual, girando el maneral. La profundidad total del piezómetro, se definió como de $60 \mathrm{~cm}$ por debajo de la profundidad del nivel freático. Una vez terminada la perforación, a la profundidad requerida, se realiza la construcción del piezómetro que consiste en colocar un tubo de PVC, con un ademe ranurado, un filtro de grava silícea, el cual se sella con bentonita. Finalmente, se cubre nuevamente con suelo y se coloca un brocal. Para mayor detalle se puede consultar Nielsen y Schalla (1991). El esquema de un piezómetro tipo se presenta en la Figura 2.

\subsection{Nivelación de brocales}

Para la configuración de elevación del nivel estático, se realizó un levantamiento topográfico empleando un equipo de nivel fijo marca Sokkia. El procedimiento consiste en posicionarse en un banco de nivel conocido, en este caso se empleó el geoposicionado por el Sistema de Agua y Saneamiento (SAS). El banco de nivel ubicado en El Tejar tiene una elevación de 8.131 m.s.n.m y el ubicado en la zona del Guasimal tiene una elevación de 6.295 m.s.n.m. A partir de este banco de nivel se traslada la cota hasta el punto de interés, empleando la técnica de nivelación (Oca, 1996).

\section{Resultados}

En este trabajo de investigación se observó que durante el año 2012 existe una recuperación de niveles freáticos someros en la temporada de lluvias. Se observaron

Tabla 1. Localización de norias de monitoreo. El punto de identificación se describe como GPS, la coordenada X, como UTMx, la coordenada Y como UTMy, la profundidad total como P.T, el nivel del terreno como NT, el promedio de la profundidad del nivel estático como Prof.NE, y tipo si es noria $(\mathrm{N})$ o piezómetro $(\mathrm{Pz})$.

\begin{tabular}{ccccccc}
\hline GPS & UTMx & UTMy & PT & NT & Prof. NE & Tipo \\
\hline 294 & 798672 & 2112415 & 3.00 & 4.46 & 1.61 & $\mathrm{~N}$ \\
299 & 798343 & 2110302 & 6.00 & 6.14 & 2.89 & $\mathrm{~N}$ \\
303 & 799023 & 2110765 & 7.59 & 7.67 & 5.70 & $\mathrm{~N}$ \\
304 & 799046 & 2112119 & 8.00 & 5.77 & 3.35 & $\mathrm{~N}$ \\
305 & 799264 & 2109512 & 7.00 & 6.59 & 4.53 & $\mathrm{~N}$ \\
311 & 798327 & 2109383 & 6.37 & 7.03 & 3.03 & $\mathrm{~N}$ \\
314 & 796997 & 2110192 & 6.00 & 6.81 & 2.46 & $\mathrm{~N}$ \\
316 & 797403 & 2108442 & 8.00 & 8.10 & 3.65 & $\mathrm{~N}$ \\
322 & 801790 & 2110508 & 5.56 & 3.95 & 2.06 & $\mathrm{~N}$ \\
324 & 801508 & 2107153 & 7.56 & 8.10 & 4.78 & $\mathrm{~N}$ \\
327 & 801080 & 2107362 & 10.39 & 9.32 & 7.05 & $\mathrm{~N}$ \\
328 & 800978 & 2107461 & 9.55 & 9.14 & 6.67 & $\mathrm{~N}$ \\
329 & 800633 & 2107717 & 8.00 & 7.26 & 4.00 & $\mathrm{~N}$ \\
332 & 799933 & 2107162 & 7.81 & 8.66 & 6.90 & $\mathrm{~N}$ \\
336 & 801778 & 2113217 & 5.00 & 3.10 & 1.30 & $\mathrm{~N}$ \\
342 & 799509 & 2107493 & 8.74 & 6.86 & 5.38 & $\mathrm{~N}$ \\
346 & 797841 & 2111773 & 5.31 & 5.37 & 1.94 & $\mathrm{~N}$ \\
349 & 797877 & 2111264 & 6.33 & 6.06 & 2.70 & $\mathrm{~N}$ \\
351 & 796663 & 2109865 & 4.99 & 6.65 & 1.95 & $\mathrm{~N}$ \\
358 & 799267 & 2111043 & 6.84 & 7.23 & 4.35 & $\mathrm{~N}$ \\
363 & 797627 & 2112998 & 7.95 & 2.19 & 2.23 & $\mathrm{~N}$ \\
361 & 799983 & 2108393 & 5.32 & 3.81 & 1.77 & $\mathrm{~N}$ \\
364 & 796428 & 2112595 & 5.42 & 5.85 & 2.53 & $\mathrm{~N}$ \\
366 & 796957 & 2108425 & 6.71 & 9.54 & 4.85 & $\mathrm{~N}$ \\
369 & 799749 & 2108980 & 7.18 & 6.17 & 4.32 & $\mathrm{~N}$ \\
370 & 801460 & 2109313 & 6.47 & 5.57 & 3.53 & $\mathrm{~N}$ \\
373 & 800303 & 2107740 & 10.75 & 9.28 & 6.98 & $\mathrm{~N}$ \\
P1 & 799293 & 2111209 & 6.36 & 6.66 & 3.32 & $\mathrm{Pz}$ \\
P2 & 799028 & 2110750 & 7.60 & 7.41 & 4.89 & $\mathrm{Pz}$ \\
P3 & 798976 & 2110687 & 7.60 & 7.20 & 4.56 & $\mathrm{Pz}$ \\
P4 & 798839 & 2110302 & 6.30 & 7.02 & 3.29 & $\mathrm{Pz}$ \\
P5 & 798966 & 2109995 & 5.77 & 6.91 & 2.74 & $\mathrm{Pz}$ \\
P6 & 799903 & 2108490 & 3.20 & 2.55 & 0.78 & $\mathrm{Pz}$ \\
P7 & 800617 & 2107694 & 7.30 & 6.66 & 4.44 & $\mathrm{Pz}$ \\
P8 & 800773 & 2107721 & 6.25 & 6.73 & 3.74 & $\mathrm{Pz}$ \\
P9 & 801246 & 2107160 & 5.89 & 8.30 & 3.60 & $\mathrm{Pz}$ \\
\hline & & & & & &
\end{tabular}


ascensos del nivel estático, de mayo a septiembre, de 3 $\mathrm{m}$ en promedio, que se registraron en las 27 norias y en los 9 piezómetros, presentando una inundación por agua subterránea en el piezómetro 6 , que tuvo un período de inundación de 4 meses.

\subsection{Precipitación 2012}

La estación climatológica de El Tejar, para el año 2012, registró un promedio de las mediciones diarias del año 2012 de $5.98 \mathrm{~mm}$, siendo el día 17 de agosto de 2012 la precipitación máxima de $120 \mathrm{~mm}$. Se observa que en los meses de junio, julio, agosto y septiembre se registraron precipitaciones mayores al promedio diario, siendo éstos de $8.21 \mathrm{~mm}, 11.84 \mathrm{~mm}, 15.54 \mathrm{~mm}$ y 17.87 $\mathrm{mm}$, respectivamente. En la Figura 3 se presenta la gráfica de precipitación diaria durante 2012 .

\subsection{Variación temporal de niveles freáticos de norias}

En la Figura 4, se presenta la variación temporal de la profundidad del nivel freático de las norias para el año 2012. En la zona de estudio se registró que la profundidad varía de $0.02 \mathrm{~m}$ a $8.75 \mathrm{~m}$, con un valor medio de $3.85 \mathrm{~m}$ para el año 2012. Se observa que en promedio, en mayo, se presenta una profundidad del nivel estático de $3.11 \mathrm{~m}$ y en septiembre de $0.34 \mathrm{~m}$. En los meses de junio, julio y agosto, se presentan ascensos hasta de $2.77 \mathrm{~m}$ del nivel estático, y de septiembre a diciembre nuevamente descensos.

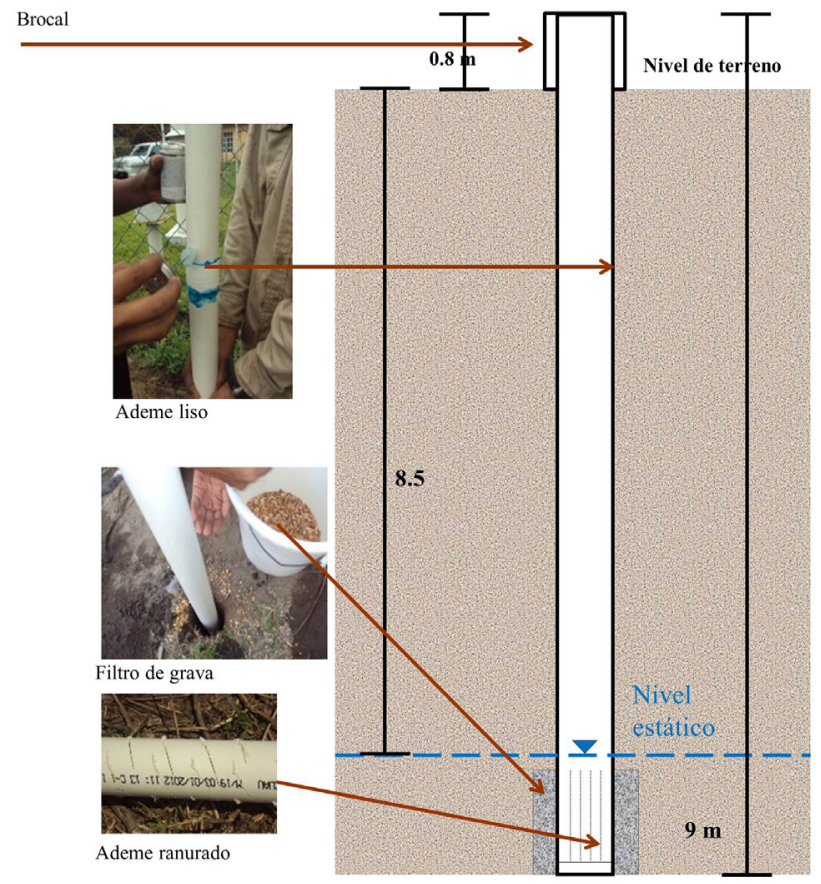

Figura 2. Esquema de un piezómetro tipo, ilustrando el ademe liso, el filtro de grava silícea y el ademe ranurado para la construcción del mismo.
4.3. Variación temporal de niveles freáticos en piezómetros

A partir de abril de 2012 se realizó el monitoreo mensual de los 9 piezómetros localizados en la zona de estudio. Se observa que se correlaciona con el comportamiento de las norias, es decir, en mayo existen descensos y en los meses de junio, julio y agosto, existen ascensos del nivel freático (Figura 5).

En el piezómetro 1, se observó un descenso de $0.35 \mathrm{~m}$ de abril a mayo, un ascenso de $1.2 \mathrm{~m}$ entre junio y agosto y un descenso de $0.7 \mathrm{~m}$ en los meses de agosto a diciembre.

En el piezómetro 2, se registró un ascenso de hasta $1.2 \mathrm{~m}$ de mayo a junio, y de septiembre a octubre hubo un descenso de $1.28 \mathrm{~m}$.

En el piezómetro 3, de mayo a junio hubo un ascenso de hasta $1.64 \mathrm{~m}$, seguido de un ligero descenso de $0.11 \mathrm{~m}$ de junio a julio, y nuevamente un ascenso de $1.39 \mathrm{~m}$ entre julio y agosto. De septiembre a octubre se presenta un descenso de $1.43 \mathrm{~m}$.

En el piezómetro 4 se tuvieron sólo registros entre enero y septiembre porque este piezómetro fue destruido por actividades antropogénicas. Durante este período se observó un descenso de abril a mayo de $0.01 \mathrm{~m}$, seguido de un ascenso de mayo a septiembre de hasta $3.52 \mathrm{~m}$.

En el piezómetro 5 se registró un descenso de $0.04 \mathrm{~m}$ entre abril y mayo, seguido de un ascenso de mayo septiembre de $3.99 \mathrm{~m}$ y nuevamente un descenso hasta diciembre de $2.56 \mathrm{~m}$.

En el piezómetro 6, de abril a mayo se presentó un descenso de $0.09 \mathrm{~m}$, seguido de un ascenso de mayo a septiembre de hasta $2.66 \mathrm{~m}$. Este piezómetro se mantuvo inundado entre julio y octubre, con un lámina de agua de $0.2 \mathrm{~m}$ en promedio

En el piezómetro 7 existe un ascenso de niveles freáticos de mayo a junio de $1.85 \mathrm{~m}$, seguido de un ligero descenso de $0.43 \mathrm{~m}$ de junio a julio y nuevamente de un ascenso de $0.56 \mathrm{~m}$, de julio a septiembre. De septiembre a diciembre se presenta un descenso de $1.79 \mathrm{~m}$.

En el piezómetro 8 se observa un ascenso de $2.43 \mathrm{~m}$ de

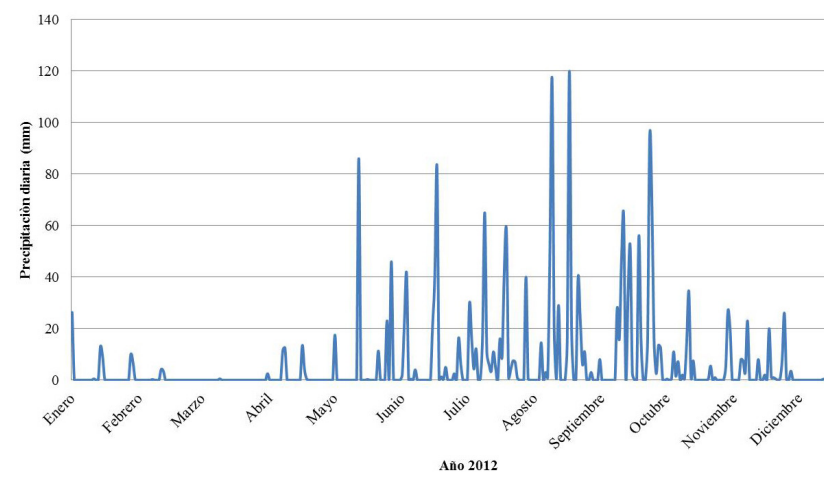

Figura 3. Precipitación diaria $(\mathrm{mm})$ de la estación climatológica El Tejar en el año 2012. 
abril a junio se registró un descenso de $1.09 \mathrm{~m}$. No se pudo continuar la medición porque fue destruido por vandalismo.

En el piezómetro 9, se observan ascensos de $3.58 \mathrm{~m}$ de abril a septiembre, y posteriormente un descenso de 1.76 $\mathrm{m}$ de septiembre a diciembre.

\subsection{Inundaciones del año 2012}

Durante el monitoreo y los recorridos de campo en 2012, se observa que de agosto a octubre se presentan los mayores ascensos del nivel estático con presencia de inundaciones. Estas zonas inundables corresponden a la zona del Guasimal

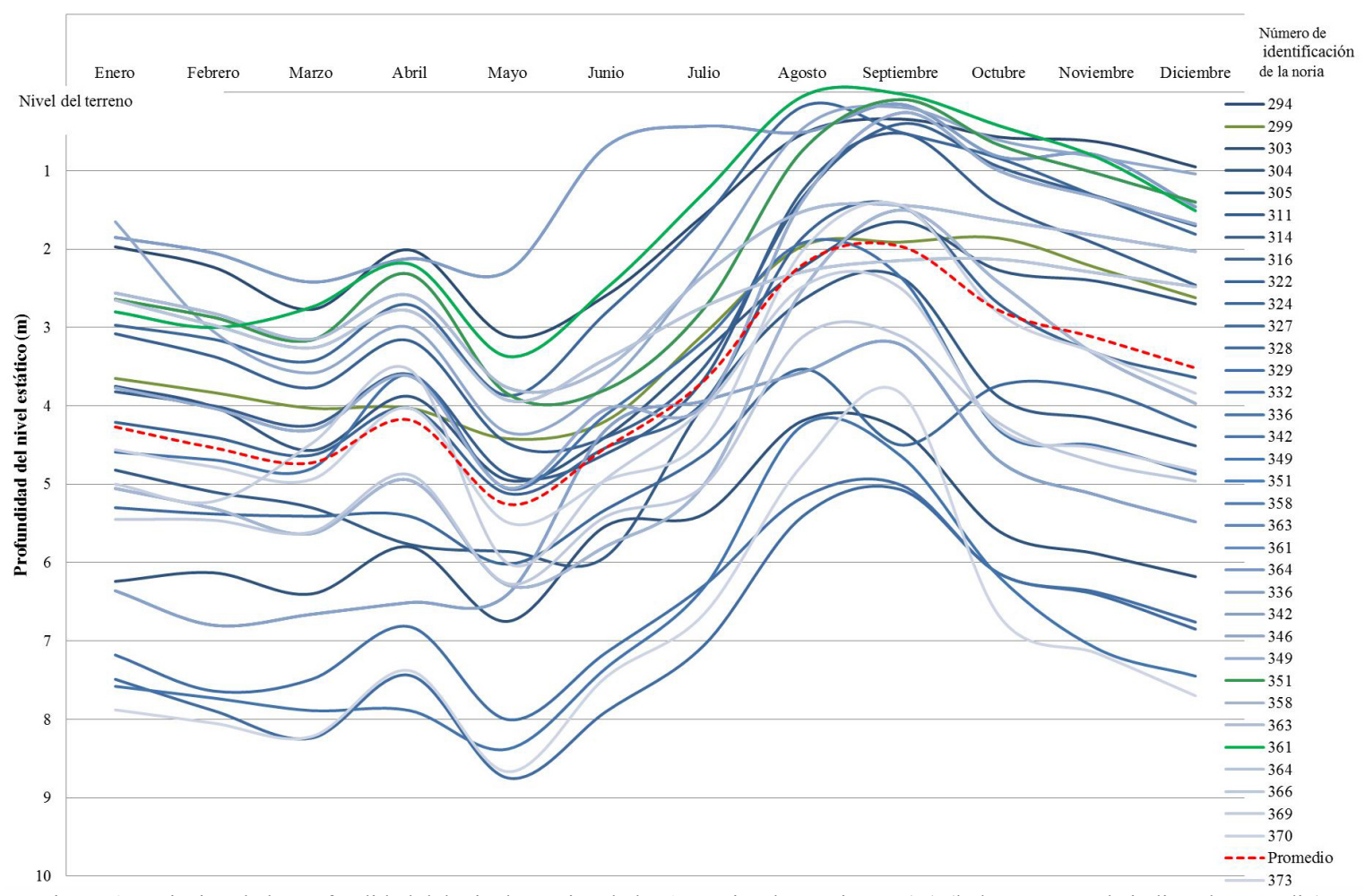

Figura 4. Variación de la Profundidad del Nivel Estático de las 27 norias de monitoreo (m) (la línea punteada indica el promedio).

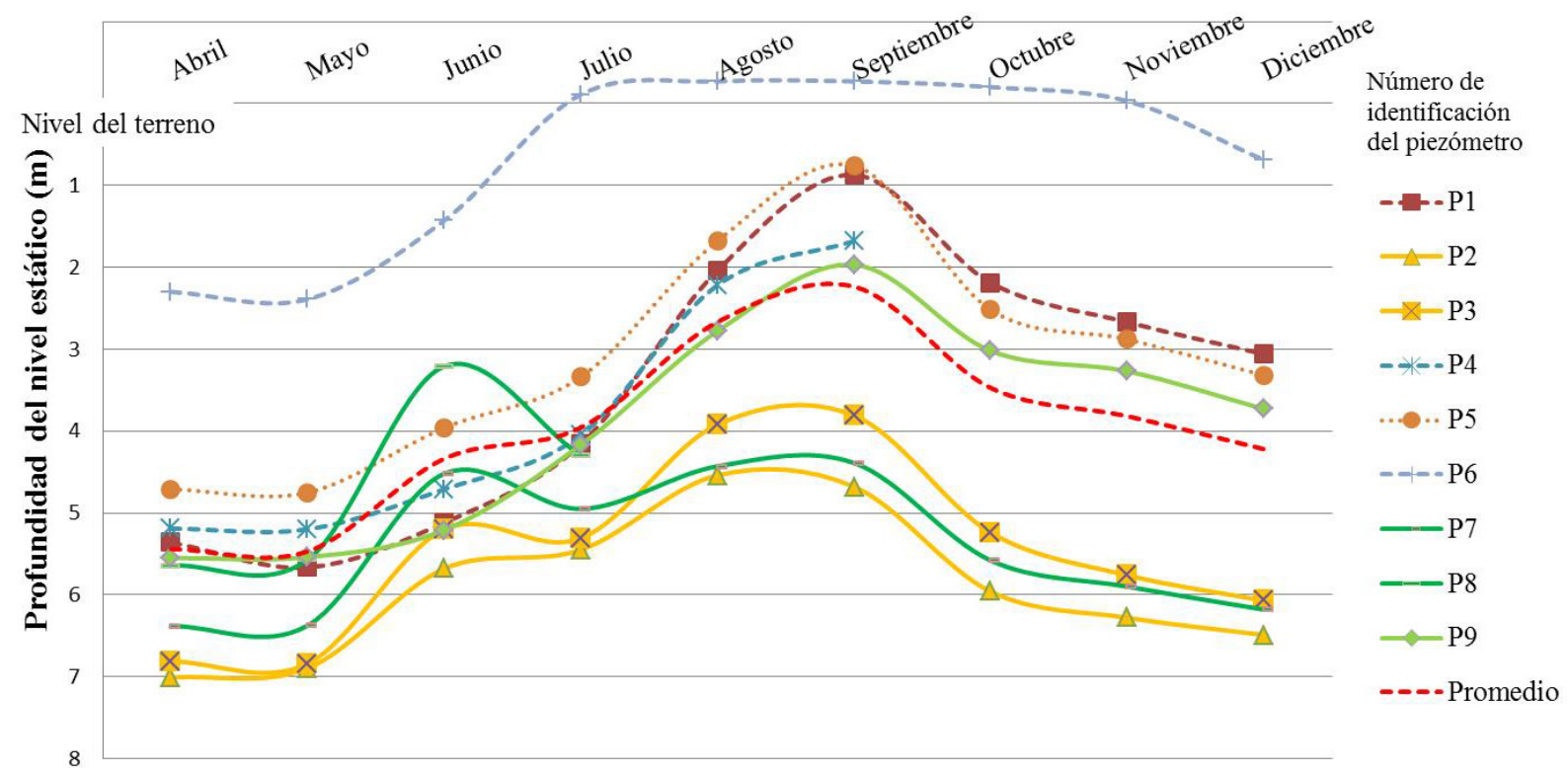

Figura 5. Variación de la profundidad del nivel estático en el 2012 de piezómetros (m). 
(piezómetro 6, noria 361), y de Rancho de El Padre (noria 351 y 299). La localización de estos sitios se presenta en la Figura 6. Los recuadros A y B, corresponden a Rancho de El Padre, y la zona C al sitio Guasimal.

En el piezómetro 6 se observa que, en mayo, el nivel estático se localizaba a $2.39 \mathrm{~m}$ de profundidad, y en septiembre, se presentó una inundación de $0.27 \mathrm{~m}$. La noria 361 , en mayo, tenía una profundidad de $3.37 \mathrm{~m}$ del nivel estático y en septiembre, de $0.02 \mathrm{~m}$, con un ascenso de 3.35 m. (Figura 7). En la noria 299, durante el recorrido de septiembre, se observa que la zona estaba inundada, en mayo tenía una profundidad del nivel estático de $4.42 \mathrm{~m}$ de profundidad y en septiembre se registró una profundidad de $1.91 \mathrm{~m}$ y se observó inundación, lo que implica un ascenso del nivel freático, el cual rellena las zonas topográficamente bajas, que corresponden a sitios donde se ha extraído suelo para la fabricación de ladrillos (Figura 8). En la noria 351, se observa que en mayo, la profundidad del nivel freático corresponde a $3.85 \mathrm{~m}$, y en septiembre a $0.09 \mathrm{~m}$. En este caso el nivel freático se encuentra sobre la superficie del terreno y se identifica una zona de inundación que se atribuye al ascenso del nivel freático (Figura 9).

\subsection{Red de flujo subterráneo}

En la figura 10 se presenta la red de flujo subterráneo para mayo de 2012 (a) y septiembre de 2012 (b). Se observa que en ambas figuras existe un flujo constante desde el Oeste hacia el Noreste y una descarga de flujo subterráneo hacia la zona del Guasimal. En mayo, sobre los ríos Jamapa y Cotaxtla, se presentan zonas localizadas de recarga de flujo subterráneo del río hacia el acuífero, y en septiembre la dirección cambia y existe un flujo subterráneo del acuífero hacia el río. Esto demuestra que independientemente del mes del año, el flujo subterráneo mantiene su dirección, salvo secciones adyacentes a los ríos Jamapa-Cotaxtla, en donde puede existir una dinámica importante entre el agua superficial y el agua subterránea. Las configuraciones de profundidad del nivel estático muestran que existe un ascenso del nivel freático en la región de mayo a septiembre. Por ejemplo, en la zona de Guasimal, en mayo se registró una profundidad del nivel estático de $4 \mathrm{~m}$ y en septiembre de $1 \mathrm{~m}$ (Figura 11).

4.6. Variación de la elevación del nivel freático en norias y piezómetros

En la Figura 12, se presenta la elevación del nivel estático para mayo y septiembre de 2012 de las 27 norias monitoreadas. En éstas se observa que, independientemente de la ubicación geográfica de las norias, se registró un ascenso generalizado de los niveles freáticos con un mínimo de $1.5 \mathrm{~m}$, un máximo de $4.8 \mathrm{~m}$ y un promedio de $3.35 \mathrm{~m}$.

En la sección de la Figura 13, se presenta la variación del comportamiento de los niveles de los piezómetros en una sección longitudinal con respecto al nivel medio del mar. Se observa que los nueve piezómetros registraron ascensos del nivel freático de mayo a septiembre, siendo el mínimo de $1.3 \mathrm{~m}$, el máximo de $4 \mathrm{~m}$ y un promedio de 2.7 m. En particular para el piezómetro 6, se observa el nivel freático por encima del nivel del terreno en septiembre, lo que denominamos una inundación por agua subterránea.

\section{Discusión}

En la zona costera de Veracruz, los niveles freáticos someros juegan un papel importante y responden a variaciones temporales. Los meses comprendidos entre junio y septiembre son los de mayor precipitación, y también en estos meses se registraron ascensos medios del nivel freático del orden de $3 \mathrm{~m}$ en las norias de monitoreo y en los piezómetros. Este hecho, sugiere que en la planicie costera del estado de Veracruz, existe una relación entre las inundaciones registradas, las precipitaciones y las fluctuaciones del nivel freático. Reza y Bravo (2011) identificaron que la precipitación es una fuente de recarga para planicies aluviales con niveles freáticos someros y que el tiempo de tránsito de la recarga en la zona no saturada varía de horas hasta meses. El hecho que se registre una incipiente recarga de los acuíferos debido a precipitación también se ha observado en otras planicies de inundación áridas, como es el caso del delta de Okavango, Botswana (Wolski y Savenije, 2006). En el parque Nacional de Las Tablas de Daimiel (España) se determinó que el aumento de los niveles freáticos por precipitación se restringe a eventos extremos (Aguilera et al., 2013). Para la zona de estudio, el ascenso de los niveles freáticos por lluvia se puede justificar por el tipo de suelo, en este caso arenoso, el cual tiene gran porosidad y facilita la recarga de los acuíferos. Este fenómeno se ha observado en niveles freáticos someros, en donde la adición de una pequeña cantidad de agua puede resultar en un aumento del nivel freático, considerando la franja de capilaridad (Gillham, 1984).

En este trabajo de investigación se presentaron tres casos en que el aumento del nivel freático produjo inundaciones por agua subterránea:

- En una zona topográficamente baja el ascenso del nivel freático produce una inundación por agua subterránea, ya que el nivel freático queda por arriba del nivel del terreno, como el que se registró en el piezómetro 6 y tuvo una duración de 4 meses.

- Una zona con niveles freáticos someros, cuya topografía ha sido afectada para extracción de material, por lo que el nivel freático intercepta las zonas de excavación, como el caso que se presentó en la noria 299, con una duración de 1 mes.

- En una planicie donde el nivel freático asciende hasta el nivel del terreno natural, produciendo una saturación del suelo, y niveles freáticos al nivel del terreno natural, como el caso que se presentó en la noria 351 con una duración de 1 mes. 


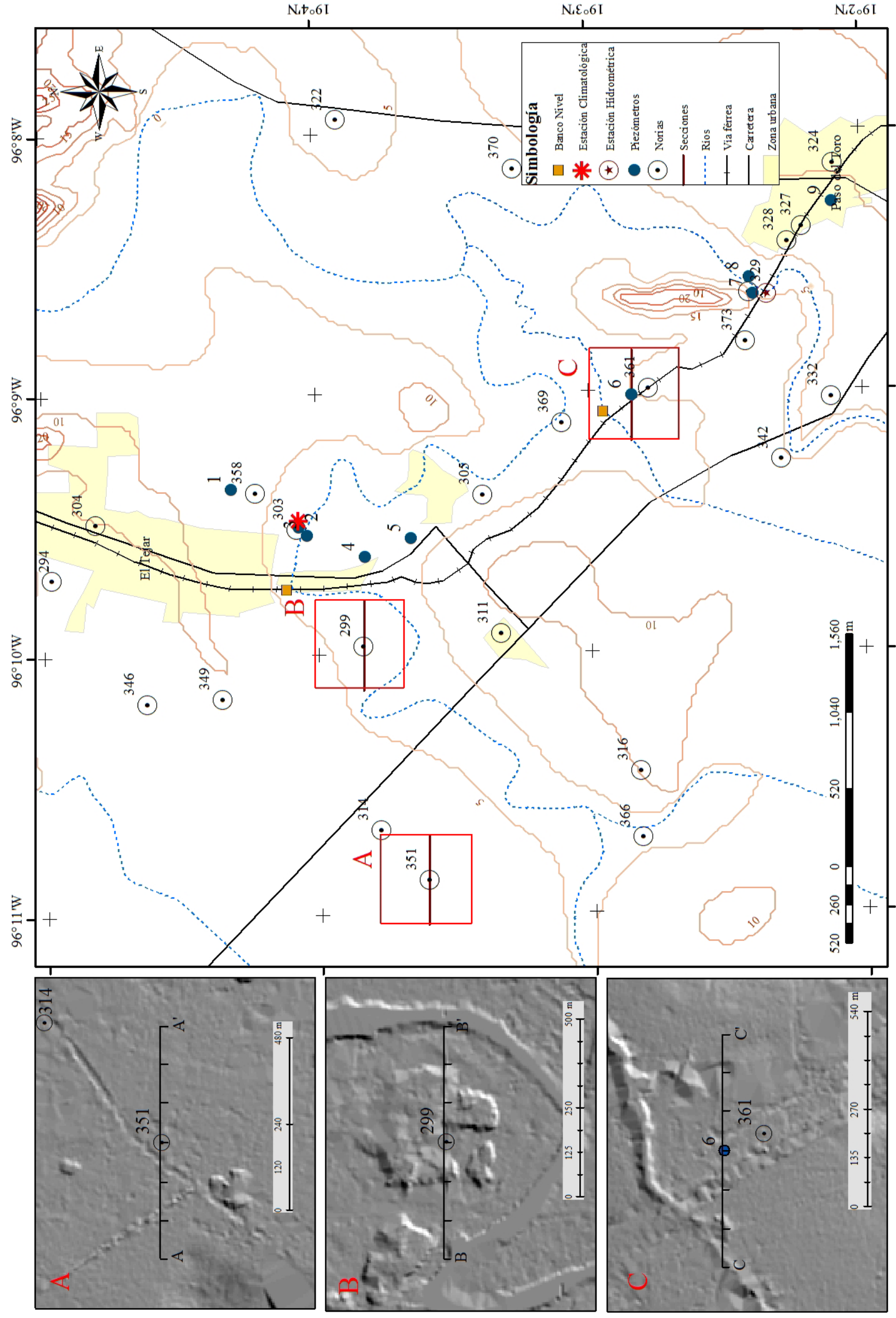

Figura 6. Localización de sitios de inundación en el 2012. La zona A y B corresponde a Rancho de El Padre y la zona C a Guasimal. 

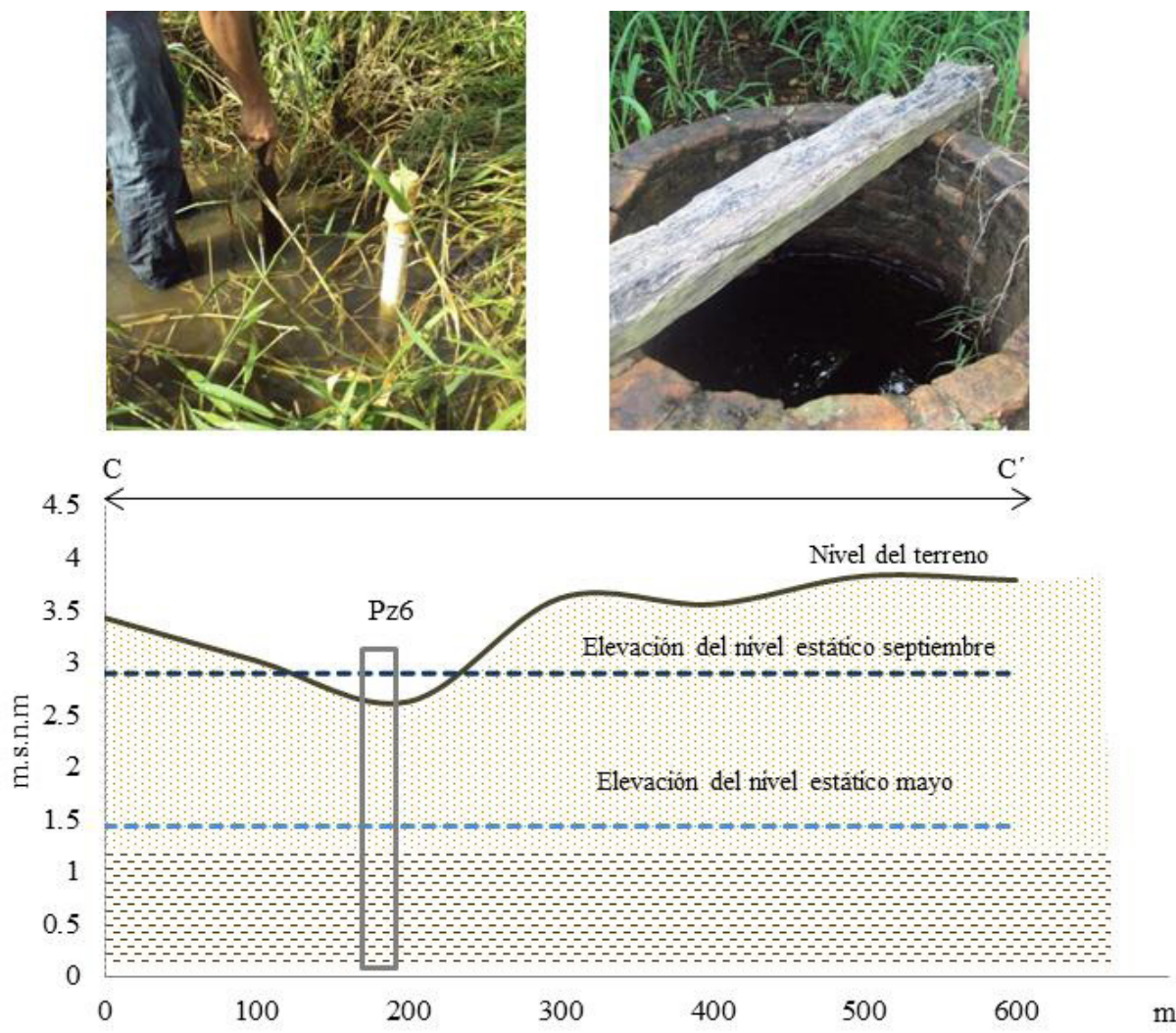

Figura 7. Piezómetro 6 (izquierda) y noria 361 (derecha) y elevación del nivel estático para secas (mayo) y lluvias (septiembre), para una sección C-C'.
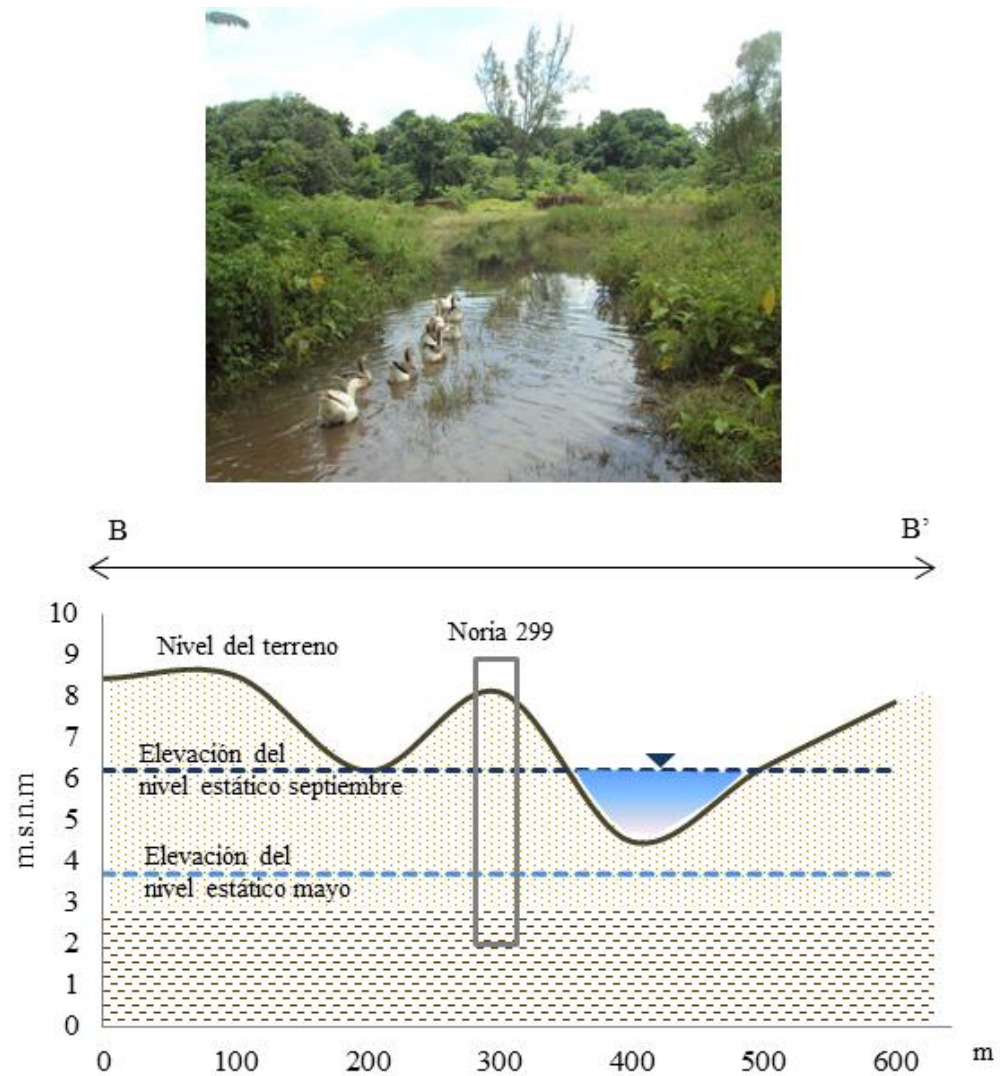

Figura 8. Noria 299 y representación de la elevación del nivel estático en secas (mayo) y lluvias (septiembre) para una sección B-B'. 

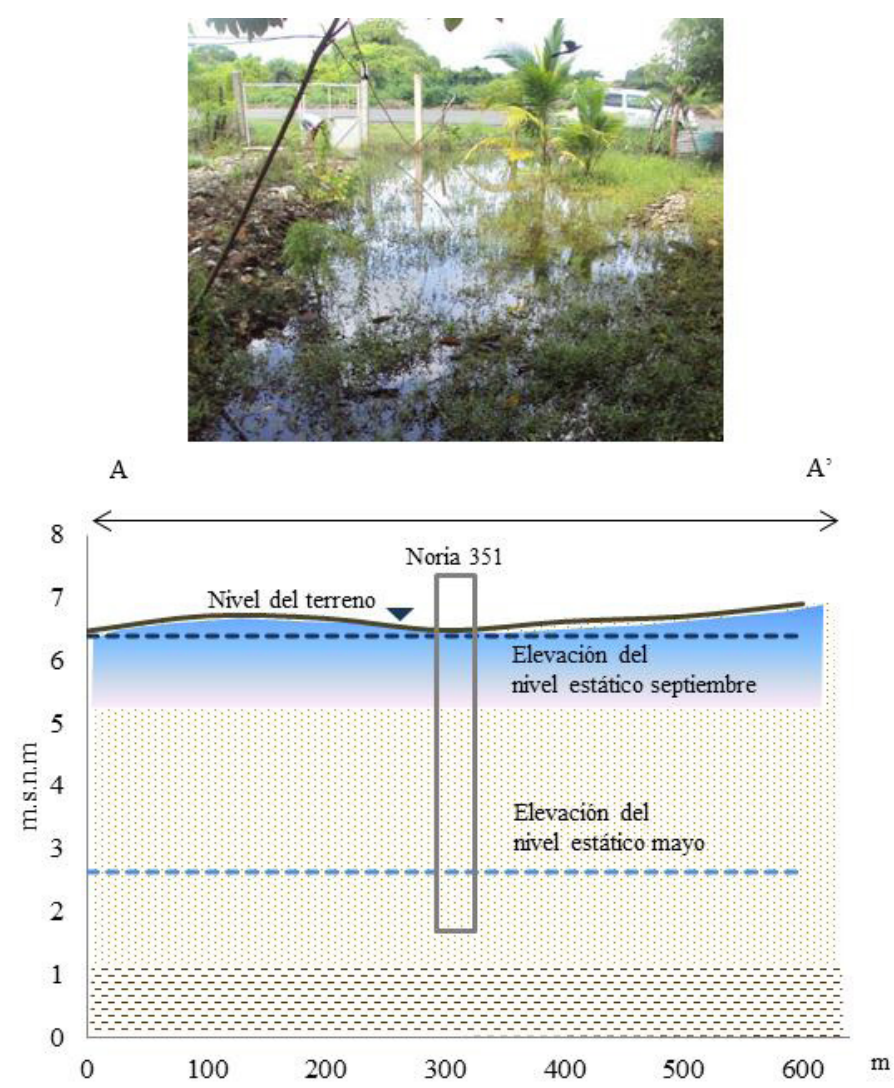

Figura 9. Noria 351 y representación de la elevación del nivel estático en secas (mayo) y lluvias (septiembre) para una sección A-A'.

En los tres casos presentados, el ascenso del nivel freático debido a precipitación dio origen a la inundación por agua subterránea, siendo zonas que no son adyacentes a los cursos de los ríos. Esto debe ser tomado en cuenta en el manejo de riesgo por inundaciones debido a que las medidas estructurales tradicionales, como bordes de protección, no aplican a las inundaciones por agua subterránea, así como debido a actividades antropogénicas (como el caso de extracción de materiales) que pueden dar origen a tener zonas inundables donde antes no existían.

Las inundaciones por agua subterránea se pueden presentar también en zonas kársticas (Escolero et al., 2007), en depósitos superficiales permeables con conectividad hidráulica de una corriente de agua o el mar y por el ascenso del nivel freático producido por una precipitación extrema (Cobby et al., 2009). Una característica para identificar las inundaciones por agua subterránea es su duración, permaneciendo el nivel de inundación hasta por tres meses debido a una re-saturación del suelo (Aguilera et al., 2013). Una de las implicaciones que tiene la duración de la inundación es económica, en la evaluación de daños que incrementan el costo por pérdidas 3.6 veces más en zonas urbanas, respecto a las inundaciones superficiales (Green, 2003; Green et al., 2006). El ascenso de nivel freático de $0.5 \mathrm{~m}$, en un acuífero de materiales granulares, puede afectar el diseño geotécnico de las construcciones subterráneas en ciudades que se localizan cerca de la costa (Oyedele et al., 2009). En el acuífero granular de Oxford, con niveles freáticos de $1-2 \mathrm{~m}$ de profundidad, la inundación por agua subterránea es un indicador de que una inundación más extensa puede ocurrir (Macdonald et al., 2007), es decir, la extensión de una inundación superficial depende en gran medida de los niveles antecedentes de agua subterránea (Cobby et al., 2009). Alconada et al. (2010) evidenciaron que el origen de inundaciones se debe a zonas de descarga de flujos locales e intermedios, en una zona de médanos, en donde los niveles freáticos varían de unos cuantos $\mathrm{cm}$ hasta $5 \mathrm{~m}$ de profundidad, por lo que la componente subterránea representa una aportación importante originando inundaciones por agua subterránea.

Con base en la metodología utilizada en esta investigación, se pudo establecer que los meses de enero a mayo y de octubre a diciembre constituyen el período de secas, y de junio a septiembre corresponde al periodo de lluvias. Esto se relaciona con fluctuaciones en el nivel freático, con ascensos y descensos de entre 2 y $3 \mathrm{~m}$, tanto en norias como de piezómetros. Esta variación se puede relacionar con el aporte de las lluvias al acuífero, lo cual supone una recarga local hacia el acuífero más cercano por infiltración del agua de lluvia en el suelo. Ya que el método propuesto en este trabajo ha probado su validez en el estudio del agua freática en la zona piloto del estado de Veracruz, se 

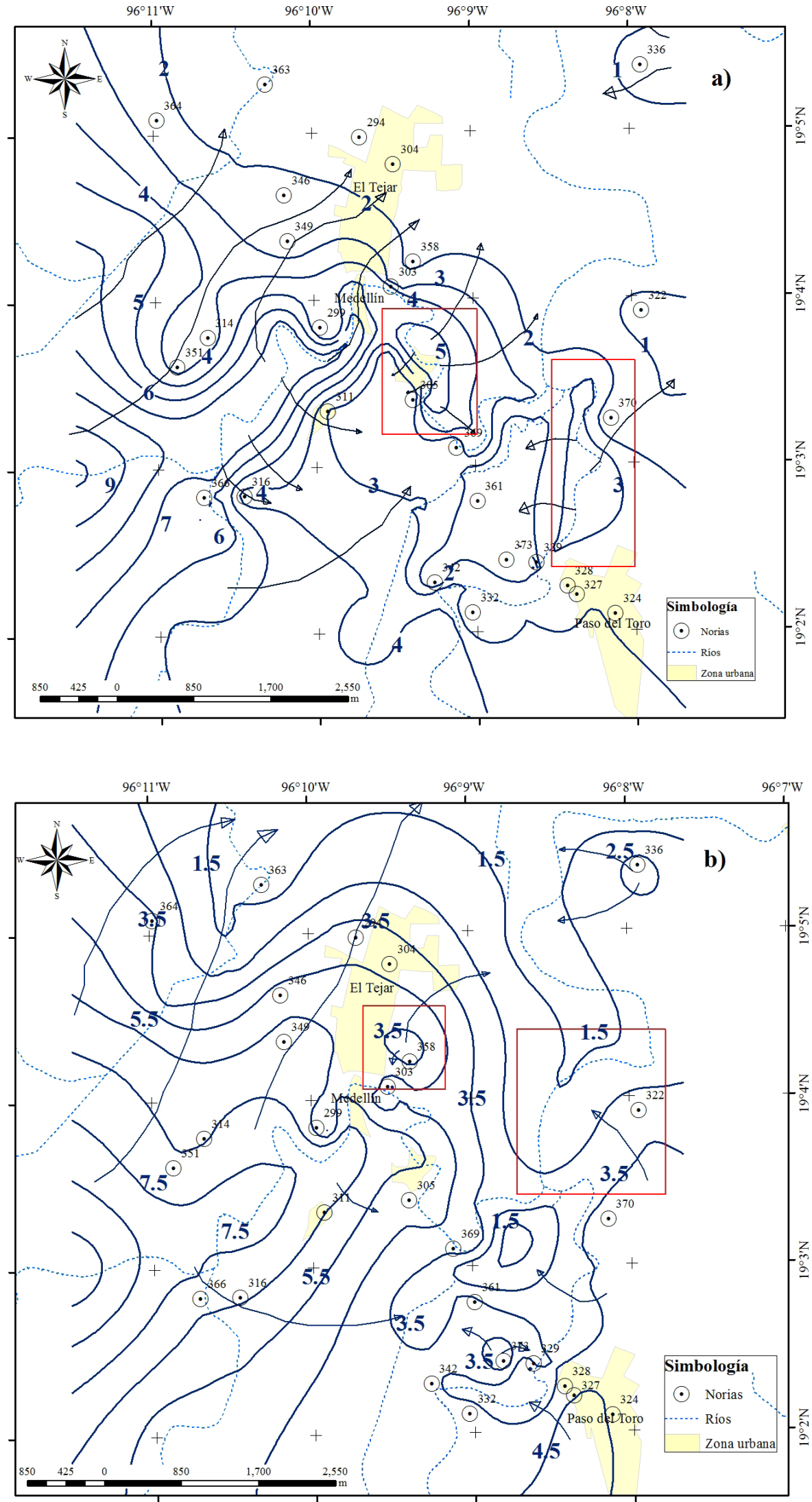

Figura 10. Red de flujo subterráneo en 2012. En a), se muestran los sitios localizados de flujo subterráneo del río al acuífero que se presentó en mayo. En b) se presenta los flujos localizados del acuífero al río que se observó en septiembre. 

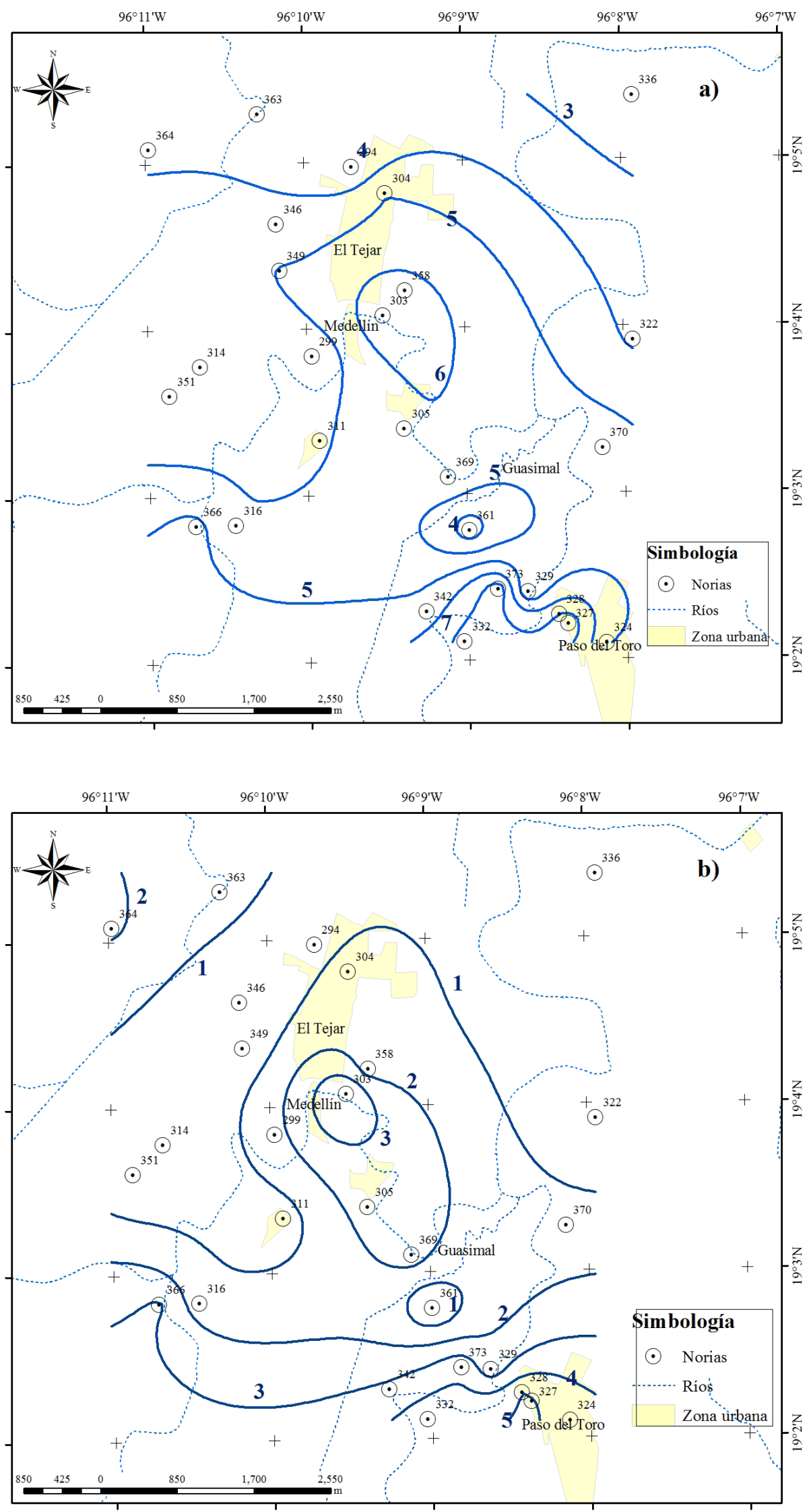

Figura 11.Profundidad del nivel estático en mayo (a) y en septiembre (b) de 2012. 


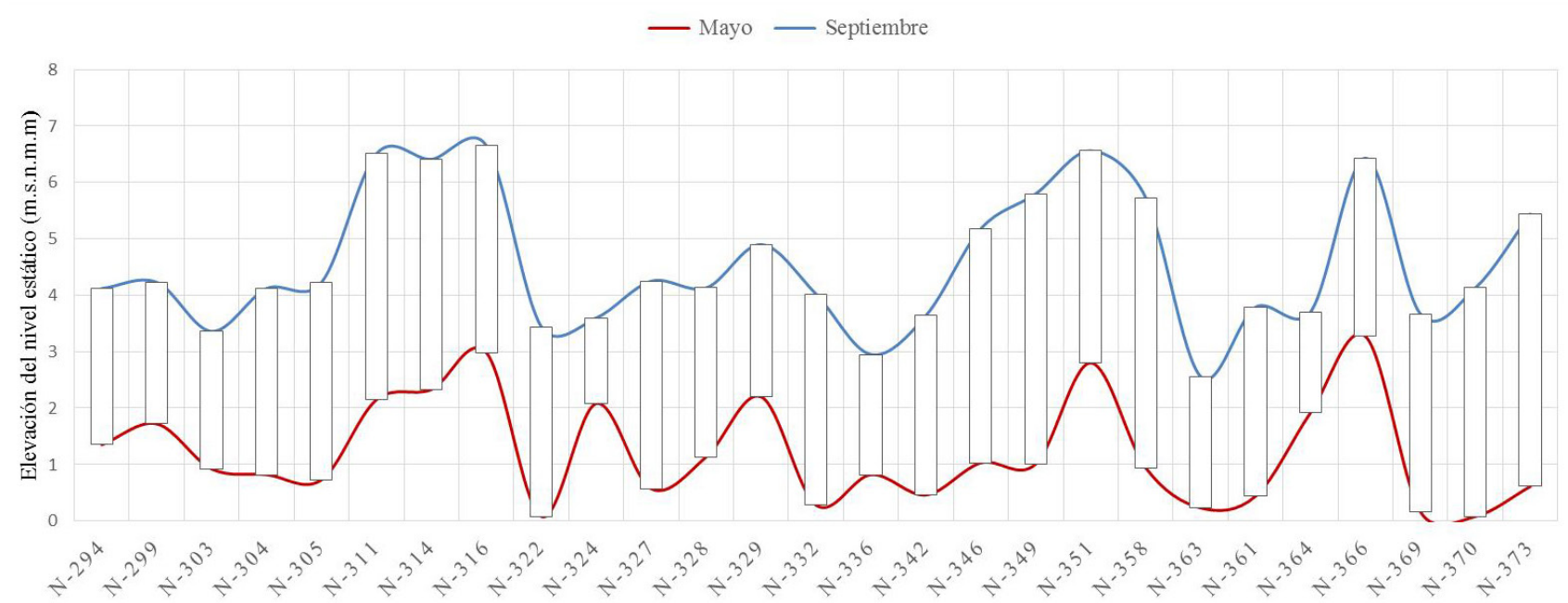

Figura 12. Variación de la elevación del nivel freático de norias para mayo y septiembre de 2012.

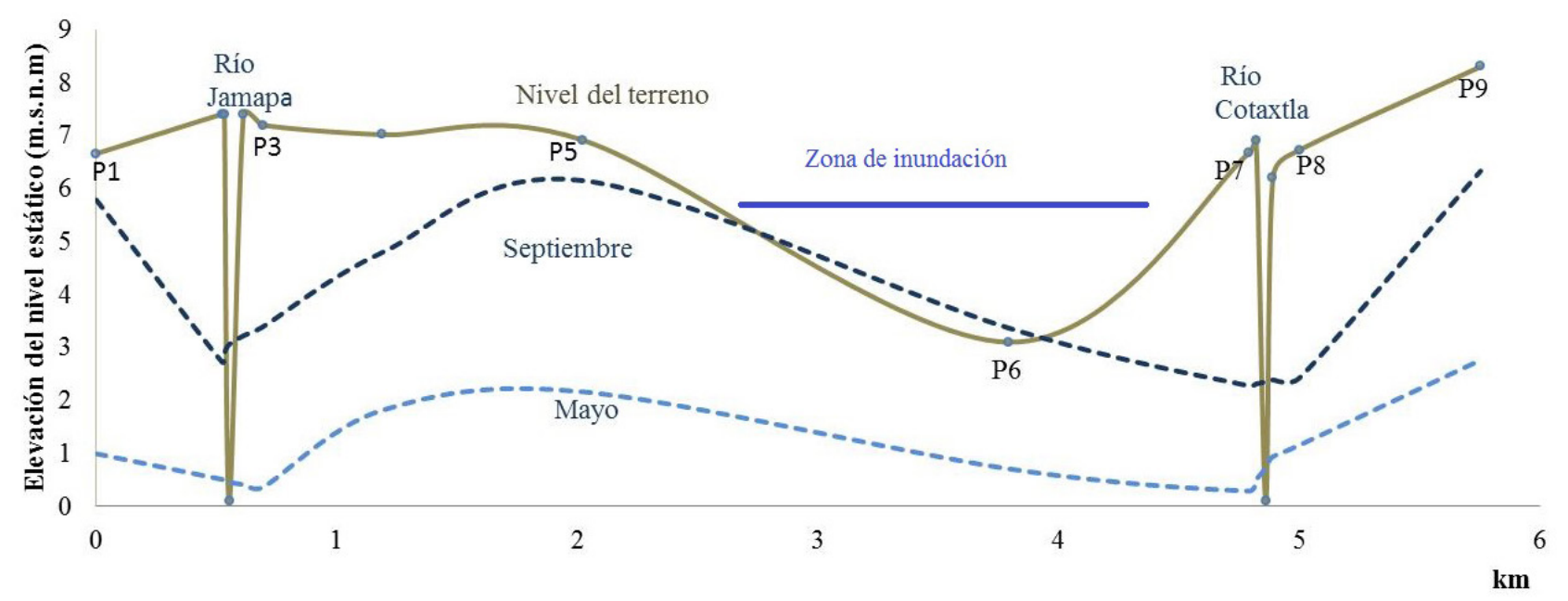

Figura 13. Variación de elevación del nivel freático en mayo y septiembre en los diferentes piezómetros (pz).

propone que las mediciones en norias y piezómetros sean tomadas en cuenta como un indicador, el cual se podría aplicar en otras planicies costeras donde se considere que existen niveles freáticos someros. El conocer los ascensos de niveles freáticos en planicies costeras es importante en el caso de nuevas construcciones, las cuáles se deben adaptar para mantener las condiciones del sistema y disminuir el riesgo de inundaciones por agua subterránea. Por otro lado estos ascensos también responden a la dinámica natural del sistema, manteniendo las condiciones ecológicas del sitio.

\section{Conclusiones}

La identificación de la variación temporal de niveles freáticos en acuíferos someros de planicies inundables es un aspecto fundamental para el manejo de riesgo en inundaciones, considerándose también las inundaciones por agua subterránea. Con base en la propuesta metodológica presentada en este trabajo de investigación, se pudo establecer que en la zona costera de Veracruz, los niveles freáticos someros juegan un papel importante y responden a variaciones temporales debido a precipitaciones con ascensos del nivel freático de $2-3$ metros, en acuíferos libres permeables, observando que en mayo se tienen los máximos descensos del nivel freático y en septiembre los máximos ascensos. Esta variación, monitoreada durante 2012, evidenció tres casos de inundaciones por agua subterránea: en el piezómetro 6, la inundación por agua subterránea tuvo un período de 4 meses y corresponde a una zona topográficamente baja, en la noria 299 se tuvo presencia de formación de cuerpos de agua por el ascenso del nivel freático en excavaciones antropogénicas, y en la noria 351 se presentó una zona de saturación del suelo. Una característica de las inundaciones por agua subterránea es el tiempo de inundación, el cual tiene repercusiones 
económicas en la evaluación de daños. En cuanto a la configuración de elevación del nivel estático, se observa que existe un flujo constante del Oeste hacia el Noreste y una descarga de flujo subterráneo hacia la zona del Guasimal que corresponde a una inundación por agua subterránea. En mayo, los ríos contribuyen al acuífero y en septiembre existe flujo subterráneo del acuífero hacia el río, conocer esta dinámica es campo de futura investigación.

Este trabajo pone en evidencia que la componente del agua subterránea debe ser tomada en cuenta para el manejo de inundaciones en zonas con presencia de niveles freáticos someros debido a que es importante identificar áreas que son susceptibles a inundaciones por agua subterránea que no necesariamente se presentan aledañas a los cauces de los ríos, lo que implica una nueva perspectiva la gestión del riesgo por inundaciones que contribuya también al ordenamiento territorial.

\section{Agradecimientos}

Este proyecto se realiza con la participación institucional de UNAM-CONAGUA- Ingeniería UV. Agradecimientos a CONACyT por la beca otorgada para realizar estudios de doctorado. A los propietarios de las norias y aforadores de CONAGUA por las facilidades para realizar las mediciones en campo. A los revisores por las sugerencias realizadas. A las señoras Lourdes Flores, Ma. Eugenia Rivera; al Sr. Amado y al Ing. Gabriel Cabrera, por el apoyo brindado para la realización del proyecto.

\section{Referencias}

Aguilera, H., Castaño, F., Moreno, L., Jiménez-Hernández, M.E., De la Losa, A., 2013, Model of hydrological behaviour of the anthropized semiarid wetland of Las Tablas de Daimiel National Park (Spain) based on surface water-groundwater interactions: Hydrogeology Journal, 21, 621-641.

Alconada, M., Fagundo. C., Carrillo. R., Hernández, P., 2010, Origin of flooding water through hydrogeochemical identification, the Buenos Aires plain, Argentina: Environmental Earth Sciences, 64, 57-71.

Belousova, A.P., 2011, Risk Assessment of Underflooding of Areas by Groundwater during Floods: Water Resources and the Regime of Water Bodies, 38, 39-46.

British Geological Survey (BGS), 2010, Groundwater flooding. Science briefing (en línea): United Kingdom, British Geological Survey, disponible en $<$ www.bgs.ac.uk/>, consultado 7 de febrero de 2014

Cobby, D., Morris, S., Parkes, A., Robinson, V., 2009, Groundwater flood risk management: advances towards meeting the requirements of the EU floods directive: Journal of Flood Risk Management, 2, 111-119.

Emergency Database (EM-DAT), 2013, The OFDA/CRED International Disaster Database (en línea): Brussels Belgium, Université catholique de Louvain, disponible en $<$ www.emdat.be/>, consultado 28 agosto de 2013.

Escolero, O., Marin, L., Domínguez, E., Torres, S., 2007, Dynamic of the freshwater-saltwater interface in a karstic aquifer under extraordinary recharge action: the Merida Yucatan case study: Environmental Geology, 51, 719-723.

European exchange circle on flood mapping (EXCIMAP), 2007, Handbook on good practice for flooding mapping in Europe: Europe, European exchange circle on flood mapping, Technical document, $60 \mathrm{p}$.

Finch, J., Marsh, T., Mckenzie, A., 2007, A prelimary risk assessment of the potential for groundwater flooding during winter of 2007/08-an update: United Kingdom, Natural Environment Research Council, Technical document, $23 \mathrm{p}$.

Gillham, R.W., 1984, The capillary fringe and its effect on water table response: Hydrogeology Journal, 67, 307-324.

Green, C.H., 2003, Handbook of Water Economics: England, John Wiley \& Sons, $46 \mathrm{p}$.

Green, C., Wilson, T., Masterson, T., Boothby, N., 2006, An assessment of the additional flood losses associate with groundwater flooding: United Kingdom, Flood Hazard Research Centre-Middlesex University, $52 \mathrm{p}$.

Hankin B., Waller, S., Astle, G., Kellagher, R., 2008, Mapping space for water: screening for urban flash flooding: J Flood Risk Management, $1,13-22$

Hueto G.J.A., 2012, Identificación espacial de la zona de inundación por desbordamiento de los ríos Jamapa y Cotaxtla en el evento del huracán Karl, 2010: México, Facultad de Ingeniería, Universidad Veracruzana, Tesina, $81 \mathrm{p}$.

Instituto Nacional de Estadística, Geografía e Informática (INEGI), 2010, Modelo del terreno Lidar (mt_e14b49.img): México, D.F., Insituto Nacional de Estadística, Geografía e Informática, 1 imagen.

Instituto Nacional de Estadística, Geografía e Informática (INEGI), 1987, Carta geológica y edafológica. Veracruz E14-3, escala 1:250000: México, D.F., Secretaría de Programación y Presupuesto, Instituto Nacional de Estadística, Geografía e Informática, 1 mapa.

International Centre for Water Hazard \& Risk Management (ICHARM), 2009, Global Trends in Water Related Disasters: an insight for policymarkers: France, The United Nations World Water Assesment Programme, Report 3, $28 \mathrm{p}$.

Macdonald, D., Hall, R., Carden, D., 2007, Investigating the interdependencies between surface and groundwater in the Oxford Area to help predict the timing and location of groundwater flooding and to optimize flood mitigation measures: England, Natural Environment Research Council -British Geological Survey, Technical report, $12 \mathrm{p}$.

McKenzie, A.A., Rutter, H., Hulbet, A., 2010, The use of elevation models to predict areas at risk of groundwater flooding: The Geological Society of London. Special Publications, 345, 75-79.

Neri, F.I, 2007, Identificación de Zonas Vulnerables a Intrusión salina en una zona costera de Veracruz: México, Instituto de GeofísicaUNAM, Tesis Maestría, 148p.

Nielsen, D.M., Schalla, R., 1991, Design and installation of groundwater monitoring wells in practical handbook of groundwater monitoring: Michigan, Lewis Publisher, $728 \mathrm{p}$.

Oca, M.M, 1996, Topografía: México, D.F, Alfa Omega, 344 p.

Ortiz, P.M.A., Oropeza, O.O., Palacio, A.A.G, D'Luna, F.A.,1992, Zonas susceptibles a desastres por fenómenos naturales 1:16000000: México, D.F., Universidad Nacional Autónoma de México, Instituto de Geografía, 1 mapa con texto.

Oumeraci, H., 2011, Research \& Development challenges towards sustainable flood defenses and flood risk management: Bahir Dar Etiopía, TU Braunschweig, Reporte técnico no publicado, 90p.

Oyedele, K.F., Ayolabi, E.A., Adeoti, L., Adegbola, R.B., 2009, Geophysical and hydrogeological evaluation of rising groundwater level in the coastal areas of Lagos, Nigeria: Bulletin of Engineering Geology and the Environment, 68, 137-143.

Reza, N.G, Bravo, H., 2011, Evaluation of correlations between precipitation, groundwater fluctuations, and lake level fluctuation using spectral methods (Wisconsin, USA): Hydrogeology Journal, 19, 801-810.

Salas, S.M.A., Jiménez, E.M., 2007, Inundaciones: México, CENAPREDSEGOB, Serie Fascículos, 56 p.

Tejeda, M.A., Ochoa, M.C., 2007, Presentación del libro Inundaciones 2005 en el Estado de Veracruz (resumen) en $2^{\circ}$ Foro Medio Ambiente Atmosférico: Xalapa, Veracruz, Universidad Veracruzana, 1-14. 
Tejeda, M.A., Montes, C.E., Sarabia, B.C., 2012, Las Inundaciones de 2010 en Veracruz, Vulnerabilidad y adaptación: México, Consejo Veracruzano de Investigación Científica y Desarrollo Tecnológico, $215 \mathrm{p}$.

Wolski, P, Savenije, H.H.G., 2006, Dynamics of floodplain-island groundwater flow in the Okavango Delta, Botswana: Journal of Hydrology, 320, 293-301.
Manuscrito recibido: Mayo 5, 2013.

Manuscrito corregido recibido: Marzo 14, 2014.

Manuscrito aceptado: Marzo 26, 2014. 